International Journal of Solar Thermal

Vacuum Engineering

Journal homepage: www.akademiabaru.com/stve.html

ISSN: $2716-6953$

\title{
Analysis of indoor environment and insulation performance of residential house with double envelope vacuum insulation panels
}

\author{
Takao Katsura ${ }^{1,}{ }^{*}$, Tomoya Ohara ${ }^{2}$, Taichi Kamada ${ }^{2}$, Katsunori Nagano ${ }^{1}$, Saim Memon ${ }^{3}$ \\ Division of Environmental Engineering, Faculty of Engineering, Hokkaido University, Sapporo, Japan \\ Division of Human Environmental Systems, Graduate School of Engineering, Hokkaido University, Sapporo, Japan \\ 4 Solar Thermal Vacuum Engineering Research Group, London Centre for Energy Engineering, School of Engineering, London South Bank \\ University, London, United Kingdom
}

\begin{abstract}
Double envelope vacuum insulation panels (VIPs) have a possibility to significantly increase the service lifetime. In this paper, double envelope VIPs were produced and installed in the residential house. The performance of installed VIPs was evaluated by using the measuring data of heat flux meter. In addition, the total energy, the heating load and the indoor thermal environment of this house were measured and analysed. The average heating load and the average temperature difference between room temperature and ambient air temperature on the representative day was $2.49 \mathrm{~kW}$ and $29.9^{\circ} \mathrm{C}$, respectively. The heat loss coefficient per floor area was estimated as $0.69 \mathrm{~W} /\left(\mathrm{m}^{2} \mathrm{~K}\right)$ and it was almost the same as the value calculated the time of design. The result of indoor environment measurement showed that the room temperature was maintained at around $20^{\circ} \mathrm{C}$ and PMV was $-0.5^{\circ} \mathrm{C}$ or higher although the outside air temperature fluctuated between $-5{ }^{\circ} \mathrm{C}$ and $-10^{\circ} \mathrm{C}$. The effective thermal conductivities of double envelop VIPs were all estimated as $0.01 \mathrm{~W} /(\mathrm{mK})$ or less. It is considered that the insulation performance of the vacuum insulation panels is maintained.
\end{abstract}

\section{Keywords:}

Vacuum insulation panels; Double

envelope; Residential house, Japan

\section{Introduction}

In order to prevent global warming, which is one of the global environmental problem, reducing the energy consumption of building becomes an important issue [1]. In Japan, it has been decided from 2025 that the compliance of energy conservation will be required also for newly built houses with the aim of further reducing energy consumption in building sector. Furthermore, the Japanese Government has set a goal of achieving ZEH (Zero-Energy-Housing) on average for new houses by 2030, therefore, it is necessary for houses to have high thermal insulation and high efficiency equipment. These are required not only for the new construction, but also for the retrofitting. Balancing the inseparably connected security of power supply and peak energy \& exergy is a major problem [2], particularly in the solar energy industry [3]. At the production level, advancements in vacuum sealing materials are critical in leading vacuum insulation panels [4,5], smart vacuum

\footnotetext{
* Corresponding author.

E-mail address: katsura@eng.hokudai.ac.jp
}

https://doi.org/10.37934/stve.3.1.1528 
windows [6,7], and solar thermal evacuated flat plate collectors [8,9]. A vacuum insulation is a decreased quantity of atmospheric-air gap between two glass panes $[10,11]$. The amount of vacuum pressure is determined by the rate at which the density of air in a space decrease. Because the mean free path between air molecules may be extended to over $1000 \mathrm{~m}$ with a decreased density of air, this offers thermal insulation $[12,13]$. When it comes to vacuum insulated glazing, obtaining a high vacuum pressure is one thing, but sustaining it for more than 20 years is quite another [14-16]. A recent development of new hermetic edge sealing materials such as fusion seal, composite edge seal [17-22], laser sealing and neutron shielding [23-25] for the development of vacuum glazing and triple vacuum glazing is promising. In recent years, the successful experimental development of translucent vacuum insulation panel has demonstrated the potential of replacing walls with it. PV system integration, as well as solar thermal collectors, are critical for achieving net-zero energy in a residential home $[26,27]$. Due to the fact that a large quantity of solar radiative heat, particularly in hot dry climates $[28,29]$, and waste heat from solar thermal collectors and electric vehicles may be harvested, as well as providing cooling to PV modules using thermoelectric [30-33]. The importance of advancing thermoelectric materials for energy harvesting applications of passive cooling [34] and converting waste heat into useful electrical power has grown over the last three decades.

The interest in the use of vacuum insulation panels (VIPs) for buildings, which have low thermal conductivity, is growing. Their high insulation performance has a possibility to reduce the construction works for insulating both of new and retrofitting buildings. The first patent for VIP was recorded as early as 1930. However, the first VIP application for buildings was in 1999 [35]. VIPs have been most used for roof insulation in building application [36]. From the 2000s to the early 2010s, some research works applying VIPs to the walls of buildings was conducted in Germany [37], Norway [38], and Canada [39]. More recently, there are several research works related to applying VIPs to the external thermal insulation composite systems [40]. These research works have established the strong potential of VIP applications in buildings [40]. On the other hand, there are still some issues with the application of VIPs to buildings, one of which is the deterioration of insulation performance. The deterioration is mainly caused by the permeation of water vapor and air into the VIP.

In order to prevent the permeation of water vapor and air into the VIP, there are main two method. The first one is the improvement of the gas barrier performance of the envelope and the other is the reduction of the pressure outside the VIP. For the latter, there is the double envelope method, in which the conventional VIP is wrapped with core materials and envelope and vacuum sealed. The double envelope method is firstly proposed by Jung et, al. They calculated the variation of effective thermal conductivity according to elapsed time and showed significant increase of service time [41]. However, there is no research works related to actually producing double envelope VIPs and the application of them to buildings.

This paper contributes to the production and installation of double envelope VIPs and installed them to a residential house. The performance of installed VIPs was evaluated by using the measuring data of heat flux meter. Furthermore, the total energy, the heating load and the indoor thermal environment of this house were analysed. 


\section{Outlines of a Residential House with Double Envelope Vacuum Insulation Panels}

\subsection{Residential house}

Fig. 1 shows an appearance of a residential house with double envelope VIPs and Table 1 indicates the outlines of residential house. The residential was completed in Sapporo, Japan in December 2019.

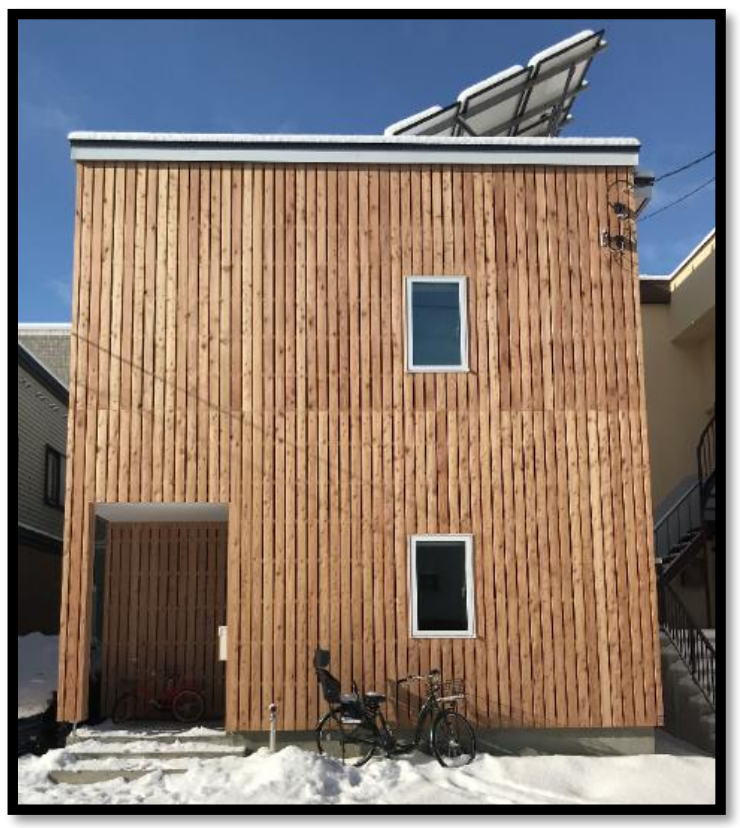

Fig. 1. An appearance of the residential house in Sapporo, Japan, with vacuum insulation panels.

Table 1

Outlines of the residential house

\begin{tabular}{|l|l|}
\hline Location & Sapporo, Japan \\
\hline Application & Residential house \\
\hline Number of floors & 2 Floors \\
\hline Structure & Wood structure \\
\hline Site area & $129 \mathrm{~m}^{2}$ \\
\hline Floor area & $119.5 \mathrm{~m}^{2}$ \\
\hline Residents & Couple and 2 children \\
\hline
\end{tabular}

The outlines of energy saving technologies installed in the residential house are indicated in Fig. 2. The double envelope VIPs were installed on the entire wall. The detail of VIPs is explained later. The low-E triple glasses filled with argon gas were used as windows. The heat recovery ventilation system was installed and reduces the ventilation heating and cooling load. In addition, the ground source heat pump (GSHP) air-conditioning system was installed as heating and cooling system. One of the features of this heating and cooling system is that one indoor unit can supply the heating and cooling to the entire house. Furthermore, the PV system with the rated power generation of $4.5 \mathrm{~kW}$ was installed. 


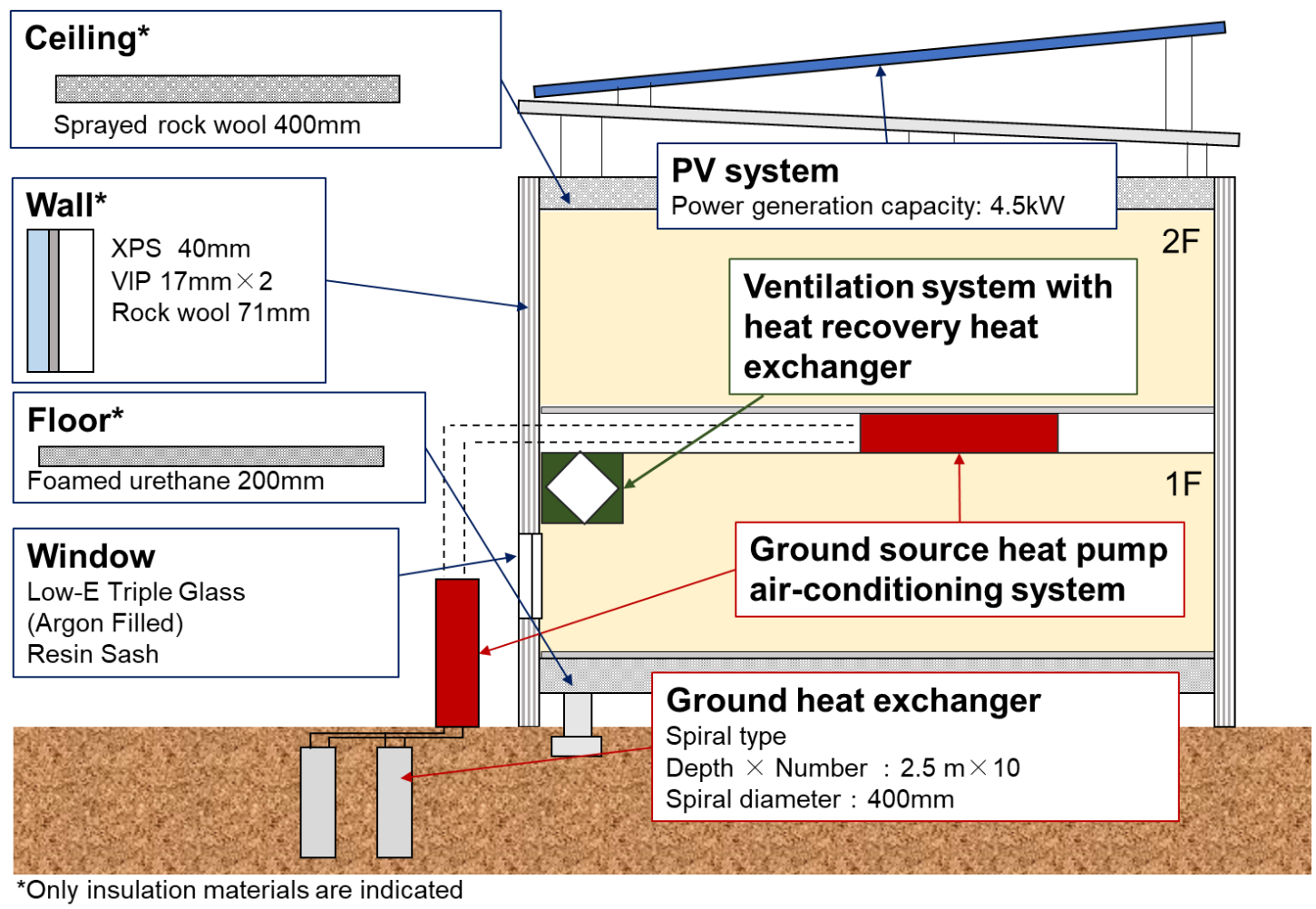

Fig. 2. Energy saving technologies installed in the residential house

\subsection{Double envelope vacuum insulation panels}

Fig. 3 shows the appearance and vertical cross section of the double envelope VIPs. As shown in Fig. 3 , the double envelope VIP can be produced by wrapping the common single envelope VIP with the core materials and envelope and vacuum-sealing. The double envelope VIPs can maintain the insulation performance of inner VIP more than 10 times compared to the normal single envelope VIPs. The reason is that the pressure around the inner VIP is extremely lower and there is almost no permeation of air and vapor to the inner VIP. The glass wool was used as core material and the getter material was placed in the inner VIP. In addition, the aluminium composite films are used as the material for the inner and outer envelopes. The centre effective thermal conductivity of a double envelope VIP was evaluated by the heat flux method and the value was $0.0025 \mathrm{~W} /(\mathrm{mK})$.
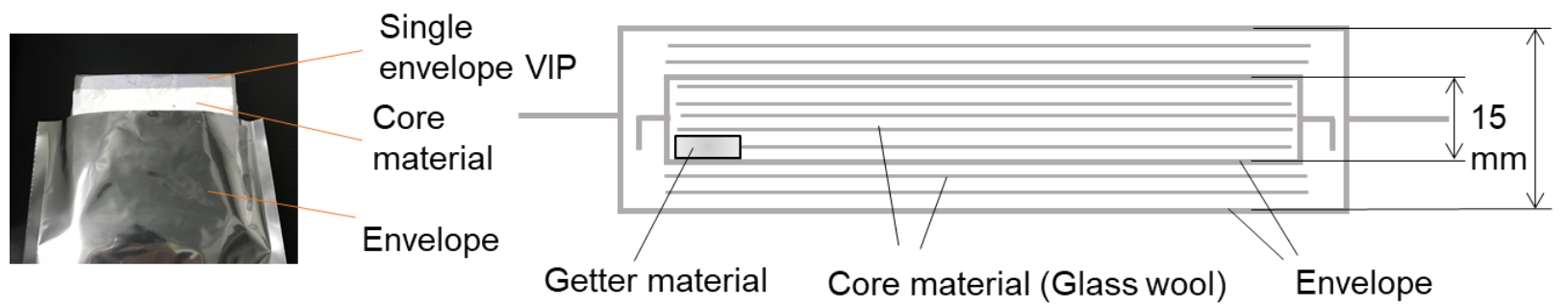

Fig. 3. Appearance (Left) and vertical cross section of a double envelope VIP (Right)

Fig. 4 introduces the application of VIPs to the residential house. The VIPs were pasted inside of the wall materials and suppressed by filling the space between the VIPs and inner wall with rock wool. Fig. 5 shows the process of construction works. First, two VIPs were overlayed (Figure 5(a)) and 
pasted inside of the wall materials (Figure 5(b)). After the pasting VIPs (Figure 5(c)), the rock wool was filled (Figure 5(d)).

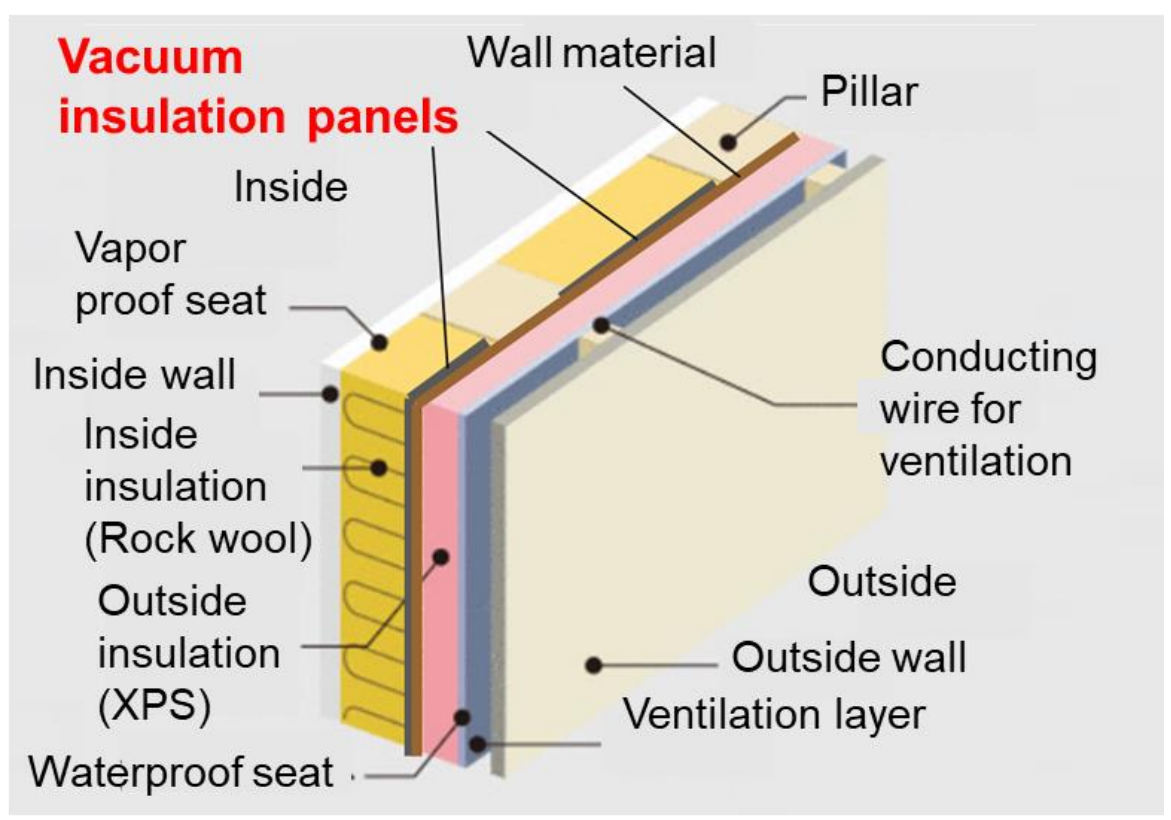

Fig. 4. Application of VIPs to the residential house

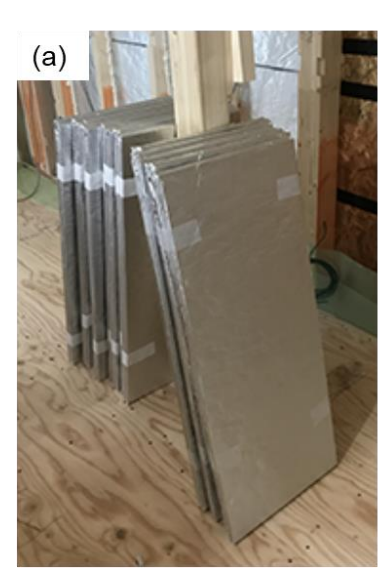

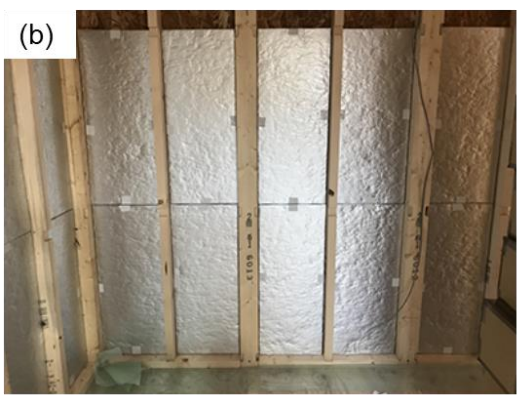

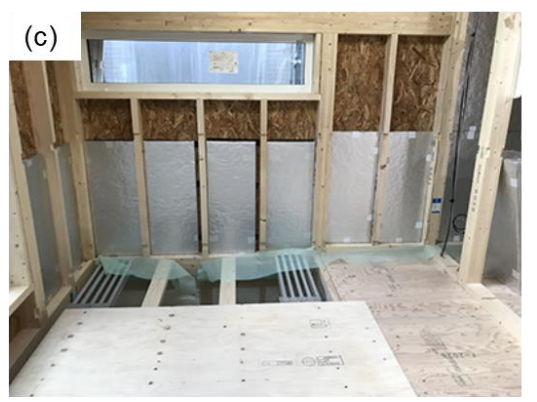

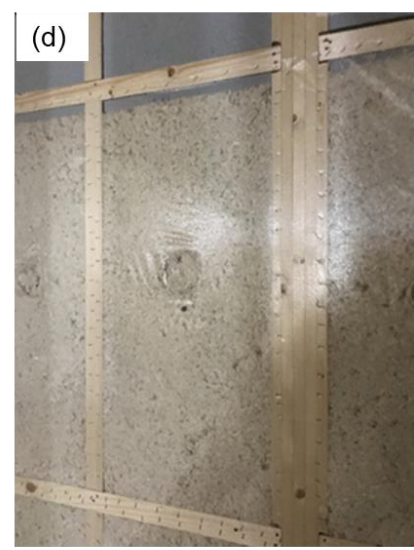

Fig. 5. Process of construction works ((a) Overlayed two VIPs, (b) and (c) VIPs pasted inside of wall materials, (d) Rock wool filled after VIPs pasted)

\section{Measurement and Analysis Method}

\subsection{Total energy, heating load, indoor environment}

The measurement items to analyse the total energy, heating load are shown in Fig. 6 . The total electric power consumption, the power generation by $\mathrm{PV}$, the electric power consumption of the GSHP air-conditioning system, and the electric power consumption of the heat pump water heater 
were monitored. Also, the inlet and outlet temperature in the primary side of the GSHP system, and the flow rate of fluid in the primary side of the GSHP system was measured. By using these measurement data, the heating load $Q_{\text {heating }}$ and cooling load $Q_{\text {cooling }}$ in this house were calculated as the following Eq. (1) and Eq. (2).

$$
\begin{aligned}
& Q_{\text {heating }}=Q_{\text {gex }}+E_{\text {com }}=c_{f} \rho_{f} G_{f}\left(T_{1 \text { in }}-T_{1 o u t}\right)+E_{\text {com }} \\
& Q_{\text {cooling }}=Q_{\text {gin }}-E_{\text {com }}=c_{f} \rho_{f} G_{f}\left(T_{1 o u t}-T_{1 \text { in }}\right)-E_{\text {com }}
\end{aligned}
$$

Here, $Q_{g e x}$ and $Q_{g i n}$ are the heat extraction rate and the heat injection rate, respectively. $c_{f}$ is the specific heat of the fluid and $\rho_{f}$ is the density of the fluid. They can be given as the function of fluid temperature. $G_{f}$ is the flow rate of fluid in the primary side of the GSHP system. $T_{1 \text { in }}$ and $T_{1 \text { out }}$ are the inlet and outlet temperature in the primary side of the GSHP system. $E_{\text {com }}$ is the electric power consumption of compressor in the GSHP air-conditioning system and this is estimated by the following Eq. (3).

$$
E_{\text {com }}=E_{A C}-E_{\text {fan }}-E_{\text {pump }}
$$

$E_{A C}$ is the electric power consumption of the GSHP air-conditioning system. $E_{\text {fan }}$ and $E_{\text {pump }}$ are the electric power consumption of a fan in the indoor unit and a pump in the primary side, respectively.

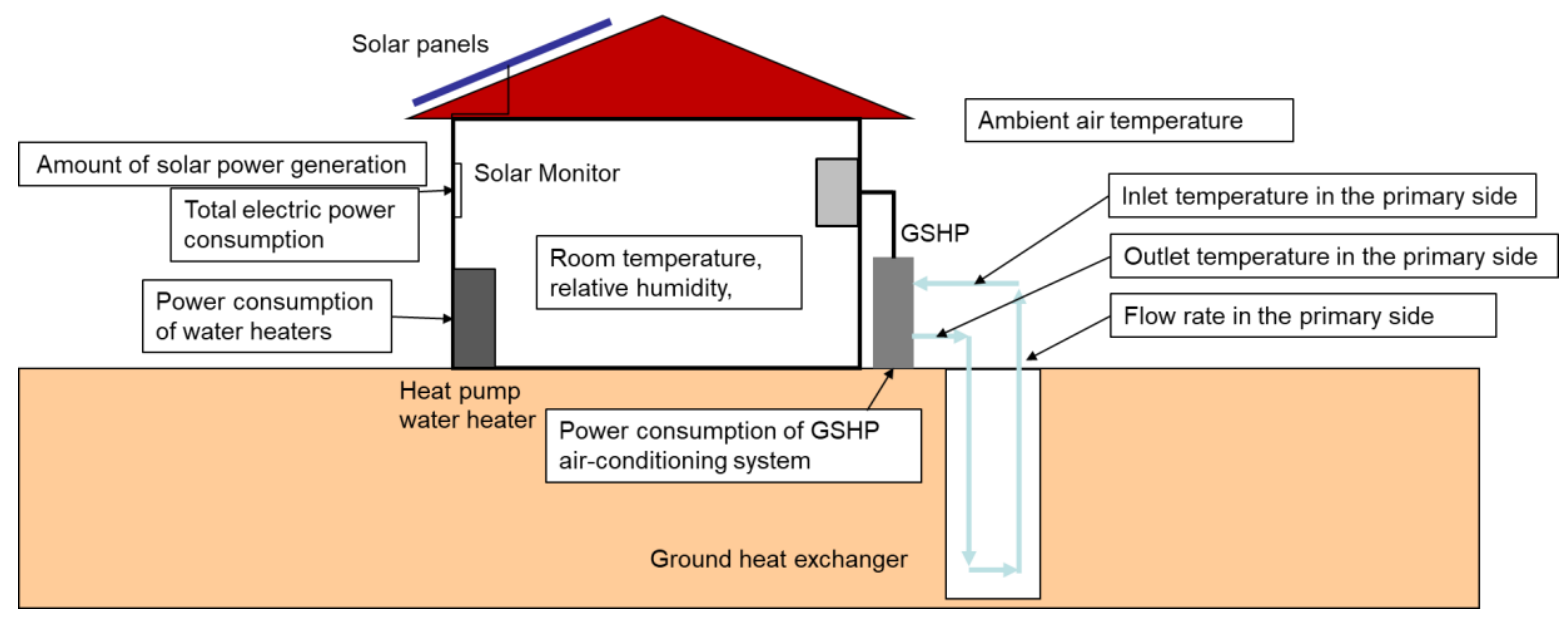

Fig. 6. Measurement items to analyse total energy and heating load

The arrangement of sensors to analyse the indoor environment is indicated in Fig 7. Temperature, globe temperature, humidity and air velocity were measured. By using these measurement data, the predicted mean vote (PMV) at each point were calculated. In addition, four points of temperature and humidity were measured. 
Temperature and humidity Heat flux meter

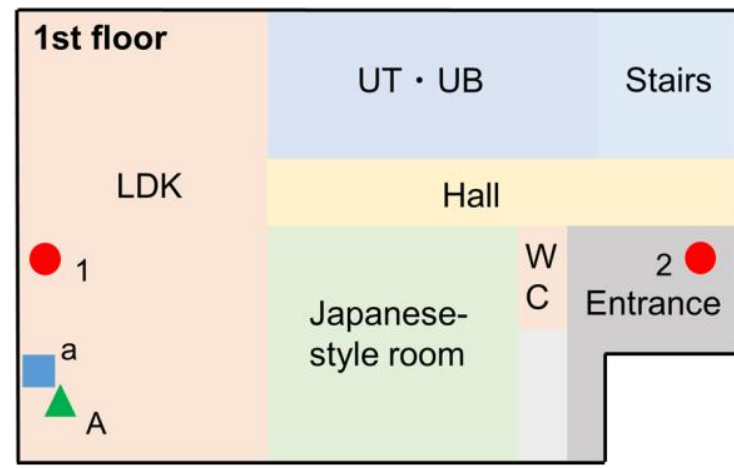

$\mathrm{N}$

$\uparrow$

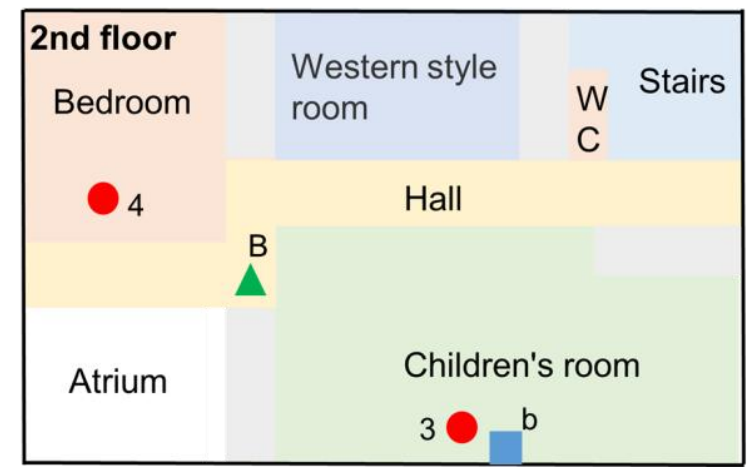

Fig. 7. Arrangement of sensors to analyse indoor environment

\subsection{Performance of double envelope vacuum insulation panels}

Heat flux meters were placed on the inside surface of wall as shown in Fig. 8, and the heat loss via the wall were measured. Also, the indoor air temperature and ambient air temperature were monitored. Then, the overall heat transfer coefficient was evaluated by using the monitoring data of heat flux, indoor air temperature, and ambient air temperature. In addition, the effective thermal conductivity of VIPs was evaluated.
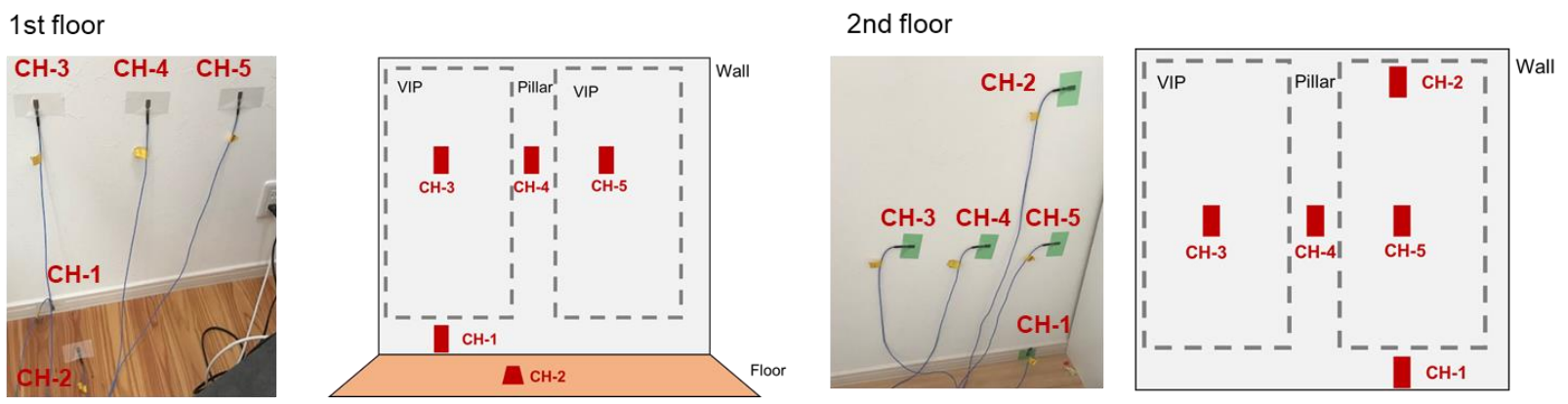

Fig. 8. Arrangement of heat flux meters on the inside surface of wall

\section{Result and discussion}

\subsection{Total energy, heating load, indoor environment}

Fig. 9a shows the monthly electric power consumption. It can be seen that the electric power for air-conditioning $(A C)$ increases and the amount of power generation from PV decreases in winter season. The power generation from PV was close to Zero on January and February because the snow covered on the PV. The power generation was approx. 3,000 kWh smaller than the electric power consumption. If the approx. $3 \mathrm{~kW}$ of PV is added, the total energy consumption becomes net-Zero in this house. Fig. $9 \mathrm{~b}$ is the breakdown of electric power consumption. In the conventional house in this area, the ratio of energy consumption for heating is more than $50 \%$. On the other hand, the ratio of energy consumption for heating decreases to $33 \%$ due to the high thermal insulation and the high efficiency GSHP air-conditioning system. 
(a)

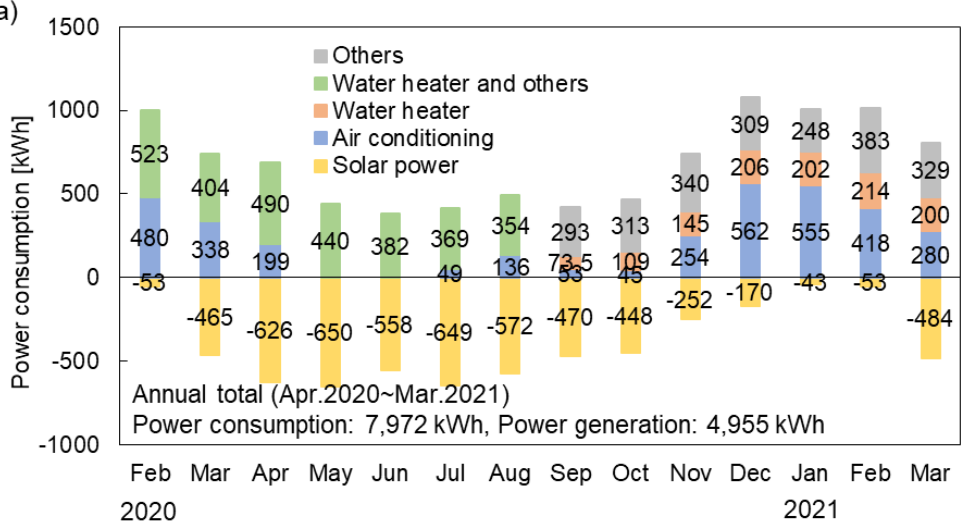

(b)

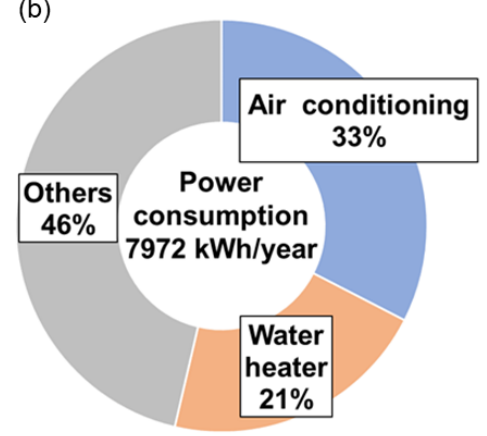

Fig. 9. (a) Monthly electric power consumption, (b) Breakdown of power consumption

Fig. 10 is the hourly variation of heating load, room temperature and ambient air temperature on January 1, 2021. The room temperature is the average value of Point A to Point D shown in Fig. 7. The average heating load $Q_{\text {heating }}$ was $2.49 \mathrm{~kW}$ and the average temperature difference between room temperature and ambient air temperature was $29.9^{\circ} \mathrm{C}$. The heat loss coefficient per floor area (= Average heating load / Average temperature difference / Floor area) was estimated as 0.69 $\mathrm{W} /\left(\mathrm{m}^{2} \cdot \mathrm{K}\right)$ and it was almost the same as the value calculated at the time of design. Fig 11a shows the monthly heating/cooling load and the average ambient air temperature, and Fig $11 \mathrm{~b}$ shows the relation. The annual total heating load was $5,763 \mathrm{kWh}$. Fig. $11 \mathrm{~b}$ indicates that the heating/cooling load can be expressed by a linear approximation formula with respect to the ambient air temperature. The absolute value of gradient coefficient $(=-0.5336)$ indicated in Fig. $11 \mathrm{~b}$ was smaller than the estimated heat loss coefficient per floor area. This is because the internal heat generation was generated by the residents' presence in the house (There was no resident on January 1, 2021).

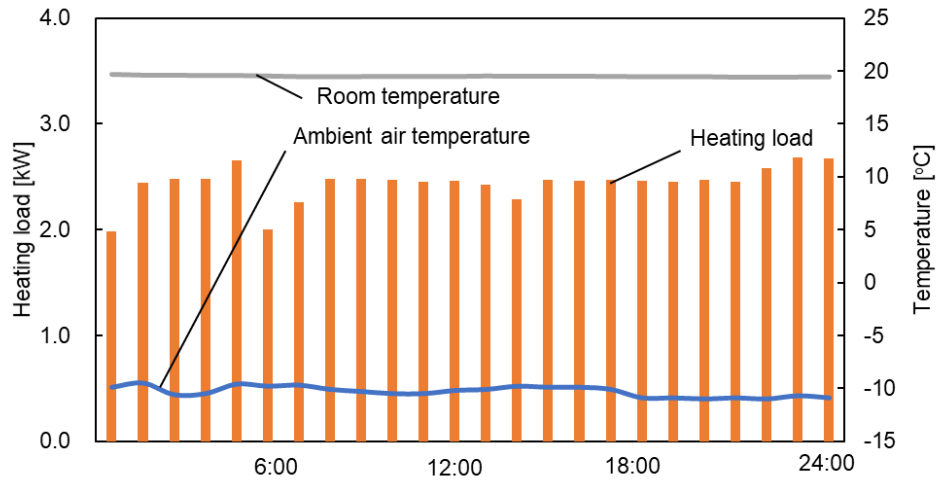

Fig. 10. Hourly variation of heating load, room temperature and ambient air temperature on January 1, 2021 

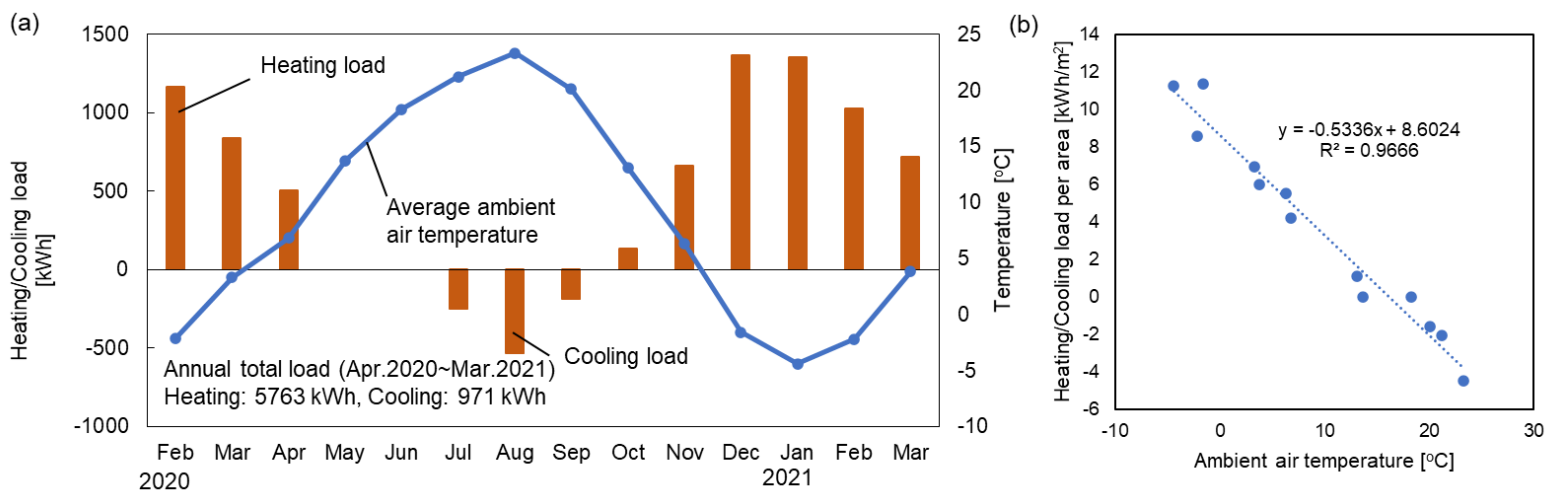

Fig. 11. (a) Monthly heating/cooling load and average ambient air temperature, (b) Relation between heating/cooling load and average ambient air temperature.

Fig. 12a and Fig. 12b show the variations of indoor air temperature, ambient air temperature, and PMV at Point $A$ and Point $B$ indicated in Fig. 5, respectively. In both cases, the outside air temperature fluctuated between $-5^{\circ} \mathrm{C}$ and $-10^{\circ} \mathrm{C}$, but the room temperature was maintained at around $20^{\circ} \mathrm{C}$ and PMV was -0.5 or higher. It can be said that the comfortable thermal environment was maintained.
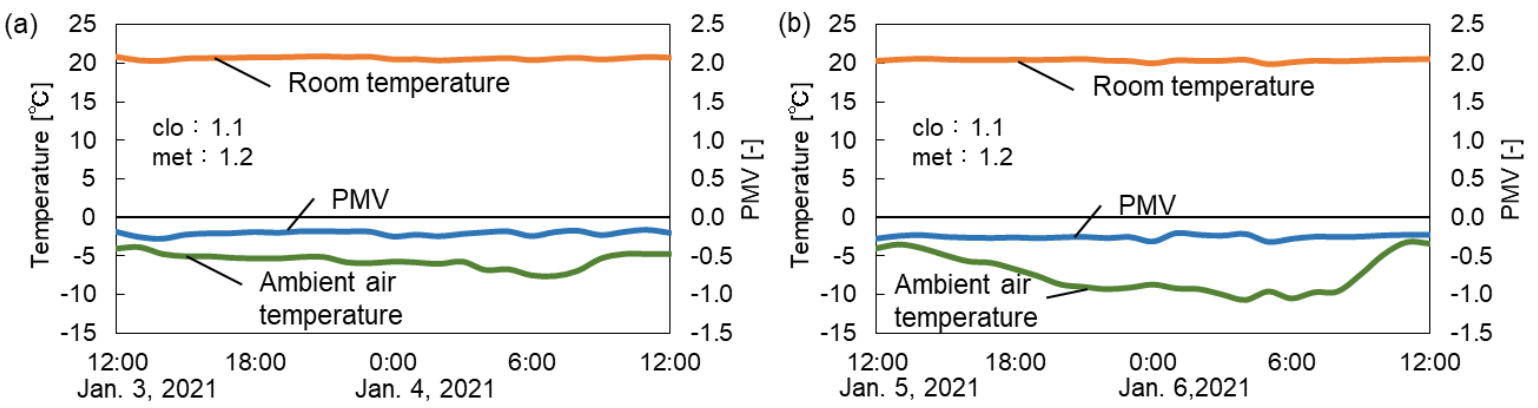

Fig. 12. Indoor air temperature, ambient air temperature, and PMV at (a) Point A and (b) Point B indicated in Fig. 5.

\subsection{Performance of double envelope vacuum insulation panels}

As measurement results on the representative day, Fig. 13a and Fig. 13b show the variations of heat flux at Point $a$ and Point $b$ indicated in Fig. 5, room temperature, and ambient air temperature, respectively. The values of heat flux at $\mathrm{CH}-3$ and $\mathrm{CH}-5$, in which the VIPs were installed, indicated small values. On the other hand, the values of heat flux at $\mathrm{CH}-1$ and $\mathrm{CH}-4$ were larger because the VIPs were not installed in these areas. By using the average values of heat flux, room temperature, and ambient air temperature, the wall overall heat transfer coefficients $K_{\text {total }}$ were calculated. In addition, the effective thermal conductivities of VIPs $\lambda_{V I P}$ were estimated by applying the following equation.

$$
\frac{1}{K_{\text {total }}}=\frac{1}{\alpha_{o}}+\frac{d_{X P S}}{\lambda_{X P S}}+\frac{d_{V I P}}{\lambda_{V I P}}+\frac{d_{r w}}{\lambda_{r w}}+\frac{1}{\alpha_{i}}
$$

Here, the values of total heat transfer coefficient of $\alpha_{o}$ and $\alpha_{i}$ are given as $20 \mathrm{~W} /\left(\mathrm{m}^{2} \mathrm{~K}\right)$ and 10 $\mathrm{W} /\left(\mathrm{m}^{2} \mathrm{~K}\right)$, respectively. The thermal conductivities of XPS $\lambda_{X P S}$ and rock wool $\lambda_{r w}$ are $0.022 \mathrm{~W} /(\mathrm{mK})$ and $0.038 \mathrm{~W} /(\mathrm{mK})$, respectively. The thermal resistance due to other wall materials is small enough 
that it is not considered in the calculation. Table 2 summarizes the estimated value of effective thermal conductivity of VIPs installed at each measurement point. Although there are differences of effective thermal conductivities due to the individual difference in the vacuum insulation panels, the effective thermal conductivities were all $0.01 \mathrm{~W} /(\mathrm{mK})$ or less. It is considered that the insulation performance of the vacuum insulation panels is maintained. Finally, the surface temperature distribution of the inside wall surface in which the VIPs were installed was measured using an infrared thermography. Fig. 14 shows the surface temperature distribution. No significant temperature drop was observed on any wall surface in which the VIPs were installed.

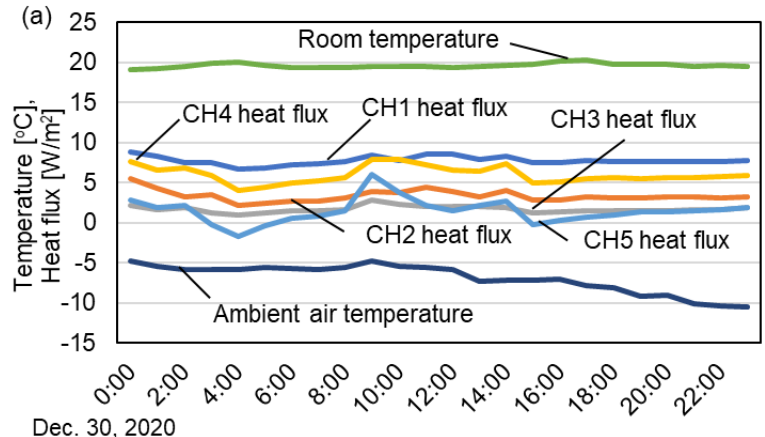

Dec. 30,2020

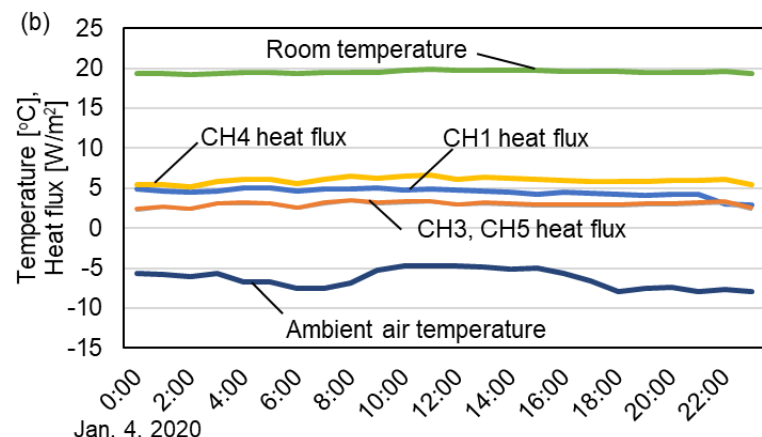

Jan. 4, 2020

Fig. 13. Variations of heat flux at (a) Point $a$ and (b) Point b indicated in Fig. 5.

\section{Table 2}

Heat flux, temperature difference, overall heat transfer coefficient, and effective thermal conductivity of VIP

\begin{tabular}{|c|c|c|c|c|}
\hline & $\begin{array}{c}\text { Heat flux } \\
{\left[\mathrm{W} / \mathrm{m}^{2}\right]}\end{array}$ & $\begin{array}{c}\text { Temperature } \\
\text { difference }[\mathrm{K}]\end{array}$ & $\begin{array}{c}\text { Wall overall heat } \\
\text { transfer coefficient } \\
{\left[\mathrm{W} /\left(\mathrm{m}^{2} \cdot \mathrm{K}\right)\right]}\end{array}$ & $\begin{array}{c}\text { Effective thermal } \\
\text { conductivity of VIP } \\
{[\mathrm{W} /(\mathrm{m} \cdot \mathrm{K})]}\end{array}$ \\
\hline $1 \mathrm{~F} \mathrm{CH}-3$ & 1.68 & 28.8 & 0.058 & 0.0026 \\
\hline $1 \mathrm{~F} \mathrm{CH}-5$ & 1.91 & 28.8 & 0.066 & 0.0030 \\
\hline $2 \mathrm{~F} \mathrm{CH}-3$ & 2.81 & 25.9 & 0.108 & 0.0063 \\
\hline $2 \mathrm{~F} \mathrm{CH}-5$ & 3.02 & 25.9 & 0.117 & 0.0072 \\
\hline
\end{tabular}
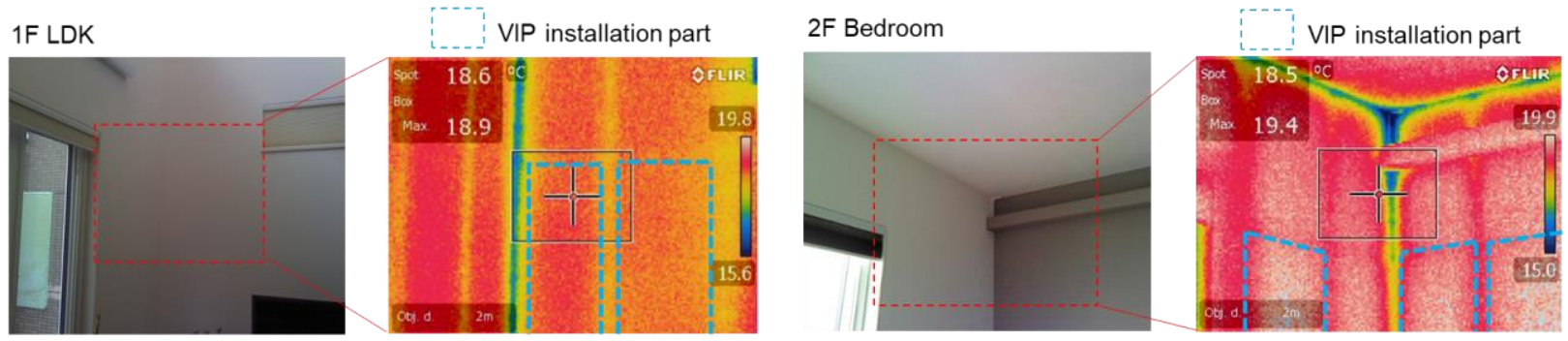

Fig. 14. Surface temperature distributions of inside wall surface

\section{Conclusions}

Double envelope VIPs were produced and installed to a residential house. The performance of installed VIPs was evaluated by using the measuring data of heat flux meter. In addition, the total energy, the heating load and the indoor thermal environment of this house were measured and analysed. As the results, the following findings were obtained. 
I. The average heating load heating load the average temperature difference between room temperature and ambient air temperature on the representative day was $2.49 \mathrm{~kW}$ and $29.9^{\circ} \mathrm{C}$, respectively. The heat loss coefficient per floor area was estimated as 0.69 $\mathrm{W} /\left(\mathrm{m}^{2} \cdot \mathrm{K}\right)$ and it was almost the same as the value calculated at the time of design. The annual total heating load was 5,763 kWh.

II. The result of indoor environment measurement showed that the room temperature was maintained at around $20^{\circ} \mathrm{C}$ and PMV was -0.5 or higher although the outside air temperature fluctuated between $-5^{\circ} \mathrm{C}$ and $-10^{\circ} \mathrm{C}$. It can be said that the comfortable thermal environment was maintained.

III. By using the measuring data of heat flux meter, the effective thermal conductivities of double envelop VIPs were all estimated as $0.01 \mathrm{~W} /(\mathrm{m} \cdot \mathrm{K})$ or less. It is considered that the insulation performance of the vacuum insulation panels is maintained.

\section{Acknowledgements}

This work was financially supported by Yashima Environment Technology Foundation and Power Academy Research Foundation (Project leader: Dr Takao Katsura). The authors also thank Hokkaido Electric power Co. Inc., T-syou Co, Ltd, SUNPOT Co, Ltd, and INOAC Housing \& Construction Materials Co., Ltd, for their assistance in the construction and monitoring.

\section{Nomenclature}

\begin{tabular}{|c|c|}
\hline C & Fluid specific heat $\left[\mathrm{Jg}^{-1} \mathrm{~K}^{-1}\right]$ \\
\hline$d$ & Thickness [m] \\
\hline$E$ & Electric power consumption [W] \\
\hline$G_{f}$ & Flow rate of fluid $\left[\mathrm{m}^{3} \mathrm{~s}^{-1}\right]$ \\
\hline$K$ & Overall heat transfer coefficient $\left[\mathrm{W} \mathrm{m}^{-2} \mathrm{~K}^{-1}\right]$ \\
\hline$Q$ & Heating / Cooling load, Heat extraction / injection [W] \\
\hline$\alpha$ & Total heat transfer coefficient $\left[\mathrm{W} \mathrm{m}^{-2} \mathrm{~K}^{-1}\right]$ \\
\hline$\lambda$ & Thermal conductivity $\left[\mathrm{W} \mathrm{m}^{-1} \mathrm{~K}^{-1}\right]$ \\
\hline $\begin{array}{c}\rho \\
\text { Subscripts }\end{array}$ & Density $\left[\mathrm{kg} \mathrm{m}^{-3}\right]$ \\
\hline$A C$ & Air-conditioning system \\
\hline $\mathrm{com}$ & Compressor \\
\hline cooling & Cooling \\
\hline$f$ & Fluid \\
\hline fan & Fan \\
\hline gex & Extraction from the ground via ground heat exchangers \\
\hline gin & Injection to the ground via ground heat exchangers \\
\hline heating & Heating \\
\hline$i$ & Inside \\
\hline 0 & Outside \\
\hline pump & Pump \\
\hline$r w$ & Rock wool \\
\hline total & Total \\
\hline VIP & Vacuum insulation panel \\
\hline$X P S$ & Extruded polystyrene foam \\
\hline
\end{tabular}

\section{References}

[1] Tjahjono, Tri, Mehdi Ali Ehyaei, Abolfazl Ahmadi, Siamak Hoseinzadeh, and Saim Memon. "Thermo-Economic Analysis on Integrated CO2, Organic Rankine Cycles, and NaClO Plant Using Liquefied Natural Gas." Energies 14, no. 10 (2021): 2849. 
https://doi.org/10.3390/en14102849

[2] Sohani, Ali, Mohammad Hassan Shahverdian, Hoseyn Sayyaadi, Siamak Hoseinzadeh, Saim Memon, Giuseppe Piras, and Davide Astiaso Garcia. "Energy and Exergy Analyses on Seasonal Comparative Evaluation of Water Flow Cooling for Improving the Performance of Monocrystalline PV Module in Hot-Arid Climate." Sustainability 13, no. 11 (2021): 6084.

https://doi.org/10.3390/su13116084

[3] Razmjoo, Armin, Meysam Majidi Nezhad, Lisa Gakenia Kaigutha, Mousa Marzband, Seyedali Mirjalili, Mehdi Pazhoohesh, Saim Memon, Mehdi A. Ehyaei, and Giuseppe Piras. "Investigating Smart City Development Based on Green Buildings, Electrical Vehicles and Feasible Indicators." Sustainability 13, no. 14 (2021): 7808. https://doi.org/10.3390/su13147808

[4] Katsura, Takao, Saim Memon, Ali Radwan, Makoto Nakamura, and Katsunori Nagano. "Thermal performance analysis of a new structured-core translucent vacuum insulation panel in comparison to vacuum glazing: Experimental and theoretically validated analyses." Solar Energy 199 (2020): 326-346. https://doi.org/10.1016/j.solener.2020.02.030

[5] Radwan, Ali, Takao Katsura, Saim Memon, Ahmed A. Serageldin, Makoto Nakamura, and Katsunori Nagano. "Thermal and electrical performances of semi-transparent photovoltaic glazing integrated with translucent vacuum insulation panel and vacuum glazing." Energy Conversion and Management 215 (2020): 112920. https://doi.org/10.1016/i.enconman.2020.112920

[6] Memon, Saim. "Design, development and thermal performance analysis of ultra-low heat loss triple vacuum glazing." In Solar World Congress 2017-Innovation for the 100\% renewable energy transformation. Abu Dhabi. (2017) ISBN 978-3-981 465 9-7-6.

https://doi.org/10.18086/swc.2017.15.04

[7] Memon, Saim. "Investigating energy saving performance interdependencies with retrofit triple vacuum glazing for use in UK dwelling with solid walls, Sustainable Development on Building and Environment." In Sustainable Development on Building and Environment: Proceedings of the 7th International Conference, 2015. ISBN-13: 9780993120701.

[8] Radwan, Ali, Takao Katsura, Saim Memon, Essam M. Abo-Zahhad, O. Abdelrehim, Ahmed A. Serageldin, Mohamed R. Elmarghany, Asmaa Khater, and Katsunori Nagano. "Development of a new vacuum-based photovoltaic/thermal collector, and its thermal and exergy analyses." Sustainable Energy \& Fuels 4, no. 12 (2020): 6251-6273. https://doi.org/10.1039/DOSE01102A

[9] Radwan, Ali, Takao Katsura, Saim Memon, Essam M. Abo-Zahhad, Ahmed A. Serageldin, and Katsunori Nagano. "Analysis of a vacuum-based photovoltaic thermal collector." Energy Reports 6 (2020): 236-242. https://doi.org/10.1016/j.egyr.2020.11.255

[10] Memon, Saim, Yueping Fang, Essam Mohamed Abo-Zahhad, O. Abdelrehim, Mohamed R. Elmarghany, Abdul Rashid Memon, Shanwen Zhang, and Amos Darko. "Factors influencing the performance parameters of vacuum glazed smart windows to net zero energy buildings." International Journal of Solar Thermal Vacuum Engineering 2, no. 1 (2020): 1-18.

https://doi.org/10.37934/stve.2.1.118

[11] Memon, Saim, Yueping Fang, and Philip C. Eames. "The influence of low-temperature surface induction on evacuation, pump-out hole sealing and thermal performance of composite edge-sealed vacuum insulated glazing." Renewable energy 135 (2019): 450-464.

https://doi.org/10.1016/i.renene.2018.12.025

[12] Memon, Saim. "Design, fabrication and performance analysis of vacuum glazing units fabricated with low and high temperature hermetic glass edge sealing materials." PhD diss., Loughborough University, 2013.

https://dspace.lboro.ac.uk/2134/14562

[13] Memon, Saim, and Philip C. Eames. "Design and development of lead-free glass-metallic vacuum materials for the construction and thermal performance of smart fusion edge-sealed vacuum glazing." Energy and Buildings (2020): 110430.

https://doi.org/10.1016/i.enbuild.2020.110430

[14] Memon, Saim, and Philip C. Eames. "Heat load and solar gain prediction for solid wall dwellings retrofitted with triple vacuum glazing for selected window to wall area ratios." In World Renewable Energy Forum, WREF 2012, vol. 6, pp. 4636-4643. ASES, 2012. ISBN: 9781622760923

[15] Fang, Yueping, Saim Memon, Jingqing Peng, Mark Tyrer, and Tingzhen Ming. "Solar thermal performance of two innovative configurations of air-vacuum layered triple glazed windows." Renewable Energy 150 (2020): 167-175. https://doi.org/10.1016/i.renene.2019.12.115 
[16] Memon, Saim, and Philip C. Eames. "Solar energy gain and space-heating energy supply analyses for solid-wall dwelling retrofitted with the experimentally achievable $U$-value of novel triple vacuum glazing." Journal of Daylighting 4, no. 1 (2017): 15-25.

https://doi.org/10.15627/jd.2017.2

[17] Memon, Saim, Farukh Farukh, and Karthikeyan Kandan. "Effect of cavity vacuum pressure diminution on thermal performance of triple vacuum glazing." Applied Sciences 8, no. 9 (2018): 1705. https://doi.org/10.3390/app8091705

[18] Memon, Saim. "Experimental measurement of hermetic edge seal's thermal conductivity for the thermal transmittance prediction of triple vacuum glazing." Case studies in thermal engineering 10 (2017): 169-178. https://doi.org/10.1016/i.csite.2017.06.002

[19] Memon, Saim, Farukh Farukh, Philip C. Eames, and Vadim V. Silberschmidt. "A new low-temperature hermetic composite edge seal for the fabrication of triple vacuum glazing." Vacuum 120 (2015): 73-82. https://doi.org/10.1016/j.vacuum.2015.06.024

[20] Memon, Saim, and Philip C. Eames. "Predicting the solar energy and space-heating energy performance for solidwall detached house retrofitted with the composite edge-sealed triple vacuum glazing." Energy Procedia 122 (2017): 565-570.

https://doi.org/10.1016/i.egypro.2017.07.419

[21] Memon, Saim. "Analysing the potential of retrofitting ultra-low heat loss triple vacuum glazed windows to an existing UK solid wall dwelling." International Journal of Renewable Energy Development (IJRED) 3, no. 3 (2014): 161-174. https://doi.org/10.14710/ijred.3.3.161-174

[22] Memon, Saim. "Thermal Conductivity Measurement of Vacuum Tight Dual-Edge Seal for the Thermal Performance Analysis of Triple Vacuum Glazing." Impact of Thermal Conductivity on Energy Technologies (2018): 133. http://dx.doi.org/10.5772/intechopen.74255

[23] Miao, Hong, Lingcong Zhang, Sixing Liu, Shanwen Zhang, Saim Memon, and Bi Zhu. "Laser Sealing for Vacuum Plate Glass with PbO-TiO2-SiO2-RxOy Solder." Sustainability 12, no. 8 (2020): 3118. https://doi.org/10.3390/su12083118

[24] Zhang, Shanwen, Min Kong, Saim Memon, Hong Miao, Yanjun Zhang, and Sixing Liu. "Thermal Analysis of a New Neutron Shielding Vacuum Multiple Glass." Sustainability 12, no. 8 (2020): 3083

https://doi.org/10.3390/su12083083

[25] Zhang, Shanwen, Min Kong, Hong Miao, Saim Memon, Yanjun Zhang, and Sixing Liu. "Transient temperature and stress fields on bonding small glass pieces to solder glass by laser welding: Numerical modelling and experimental validation." Solar Energy 209 (2020): 350-362.

https://doi.org/10.1016/i.solener.2020.09.014

[26] Memon, S., T. Katsura, A. Radwan, S. Zhang, A. A. Serageldin, E. M. Abo-Zahhad, S. Sergey et al. "Modern eminence and concise critique of solar thermal energy and vacuum insulation technologies for sustainable lowcarbon infrastructure." International Journal of Solar Thermal Vacuum Engineering 1, no. 1 (2020): 52-71. ISSN online (2716-6953). https://doi.org/10.37934/stve.1.1.5271

[27] Ahmed, Mostafa, Ali Radwan, Ahmed Serageldin, Saim Memon, Takao Katsura, and Katsunori Nagano. "Thermal Analysis of a New Sliding Smart Window Integrated with Vacuum Insulation, Photovoltaic, and Phase Change Material." Sustainability 12, no. 19 (2020): 7846.

https://doi.org/10.3390/su12197846

[28] Bensafi, Mohammed, Houari Ameur, Noureddine Kaid, Siamak Hoseinzadeh, Saim Memon, and Davide Astiaso Garcia. "Thermophysics Analysis of Office Buildings with a Temperature-Humidity Coupling Strategy Under HotArid Climatic Conditions." International Journal of Thermophysics 42, no. 8 (2021): 1-20. https://doi.org/10.1007/s10765-021-02858-1

[29] Khan, Asif, and Saim Memon. "Effect of hot-arid climatic solar energy on monocrystalline photovoltaic performance in Pakistan." International Journal of Solar Thermal Vacuum Engineering 2, no. 1 (2020): 19-39. https://doi.org/10.37934/stve.2.1.1939

[30] Memon, Saim, Maekele Mihreteab, Takao Katsura, Ali Radwan, Shanwen Zhang, Ahmed A. Serageldin, and Essam M. Abo-Zahhad. "Experimental and theoretical performance evaluation of parabolic trough mirror as solar thermal concentrator to thermoelectric generators." International Journal of Solar Thermal Vacuum Engineering 1, no. 1 (2020): 22-38. ISSN online (2716-6953).

https://doi.org/10.37934/stve.1.1.2238 
[31] Memon, Saim. "Advanced Thermoelectric Materials for Energy Harvesting Applications." .IntechOpen Publisher, London, ISBN: 978-1-78984-529-7, (2020). https://doi.org/10.5772/intechopen.77430

[32] Memon, Saim, and Khawaja Noman Tahir. "Experimental and analytical simulation analyses on the electrical performance of thermoelectric generator modules for direct and concentrated quartz-halogen heat harvesting." Energies 11, no. 12 (2018): 3315.

https://doi.org/10.3390/en11123315

[33] Memon, Saim. "Introductory Chapter: Introduction to Advanced Thermoelectric Materials for Energy Harvesting Applications", Advanced Thermoelectric Materials for Energy Harvesting Applications, IntechOpen, London. (2019). https://doi.org/10.5772/intechopen.89640

[34] Abo-Zahhad, Essam M., Shinichi Ookawara, Ali Radwan, Saim Memon, Yue Yang, M. F. El-Kady, and A. H. ElShazly. "Flow boiling in a four-compartment heat sink for high-heat flux cooling: A parametric study." Energy Conversion and Management 230 (2021): 113778.

https://doi.org/10.1016/i.enconman.2020.113778

[35] Brunner S., Ghazi Wakili K., Stahl T., and Binder C., "Vacuum insulation panels for building application Continuous challenges and development-." Energy and Buildings 85 (2014): 592-596.

https://doi.org/10.1016/i.enbuild.2014.09.016

[36] Brunner S., "Superinsulating materials present applications." Int Symp Superinsulating Mater, Brussels, 2012.

[37] Pool M., "Insulation of a mixed use building with 7 storeys in Munich with VIP." Proceedings of the 9th international vacuum insulation symposium (IVIS2009), London, UK, 17-18 September, 2009.

[38] Sveipe E., Jelle B. P., Wegger E., Uvsløkk S., Grynning S., Thue J. V., Time B., Gustavsen A., "Improving thermal insulation of timber frame walls by retrofitting with vacuum insulation panels - experimental and theoretical investigations." Journal of Building Phys 35, 2011, 168-188.

[39] MacLean D., Korn J., Mukhopadhyaya P., "Vacuum insulation panels (VIPs) arrive in northern Canada." Proceedings of the 10th international vacuum insulation symposium (IVIS-X), Ottawa, Ontario, Canada, 15-16 September, 2011, 59-67.

[40] Goncalves M., Simoes., Serra C., Flores-Colen I., "A review of the challenges posed by the use of vacuum panels in external insulation finishing systems." Applied Energy 257 (2020): 114028.

https://doi.org/10.1016/j.apenergy.2019.114028

[41] Jung H., Yeo I., and Song T., "Al-foil-bonded developing and double enveloping for application to vacuum insulation panels." Energy and Buildings 84 (2014): 595-606.

http://dx.doi.org/10.1016/i.enbuild.2014.08.045 